\title{
PLANEJAMENTO DE ENSINO DE PROFESSORES DE EDUCAÇÃO FÍSICA EM ESCOLAS PÚBLICAS DE PARIPIRANGA (BA)
}

\section{TEACHING PLANNING OF PHYSICAL EDUCATION TEACHERS IN PUBLIC SCHOOLS OF PARIPIRANGA (BA)}

\author{
Ana Larissa Carregosa Santana \\ Bacharela em Educação Física, \\ UNIAGES Centro Universitário, Paripiranga-BA, Brasil \\ E-mail: ana-larissa2009@hotmail.com
}

\author{
Davi Soares Santos Ribeiro \\ Mestre em Educação Física, \\ Docente do UNIAGES Centro Universitário, Paripiranga-BA, Brasil \\ E-mail: profdavi@live.com \\ ORCID: https://orcid.org/0000-0001-9816-2566
}

Recebido: 09/06/2021 - Aceito: 09/06/2021

\begin{abstract}
Resumo
O planejamento é fundamental para sistematizar e organizar os conteúdos de acordo com a realidade escolar. Nesse sentido, o professor deve enfatizar o planejamento para uma prática pedagógica eficaz e com resultados positivos. O estudo tem o objetivo de analisar o planejamento de ensino de professores de Educação Física do munícipio de Paripiranga-BA. Trata-se de uma pesquisa de campo com abordagem quantitativa. A amostra foi composta por 3 professores graduados em Educação Física. Observou-se que os professores são licenciados em Educação Física e planejam suas aulas com base nos PCNs, DCNs e BNCC, porém percebeu-se ausência do espaço físico e de materiais adequados no ambiente escolar que dificultam no desenvolvimento das aulas. Conclui-se que os professores demonstraram a preocupação em planejar os conteúdos da Educação Física aos seus alunos.
\end{abstract}

Palavras-chave: planejamento; ensino; Educação Física.

\section{Abstract}

Planning is essential to systematize and organize content according to school reality. In this sense, the teacher must emphasize planning for an effective pedagogical practice with positive results. The study aims to analyze the teaching planning of Physical Education teachers in the municipality of Paripiranga-BA. It is a field research with a quantitative approach. The sample consisted of 3 teachers graduated in Physical Education. It was observed that the teachers are licensed in Physical Education and plan their classes based on the PCNs, DCNs and BNCC, 
however it was noticed the absence of physical space and adequate materials in the school environment that hinder the development of classes. It is concluded that the teachers showed the concern to plan the contents of Physical Education to their students.

Keywords: planning; teaching; physical education.

\section{Introdução}

O planejamento é um processo de sistematização e organização das ações do professor. Segundo Libâneo (2013) é um instrumento da racionalização do trabalho pedagógico que articula a atividade escolar com os conteúdos do contexto social.

O ato de planejar é um instrumento do processo educacional que estabelece e determina prioridades básicas, organiza ações e meios necessários para a efetivação de metas e objetivos da educação (MENEGOLLA \& SANT'ANNA, 2001). No planejamento, os conteúdos selecionados, organizados e sistematizados devem promover uma concepção cientifica do mundo, bem como a formação de interesses e a manifestação de possibilidades e aptidões.

A Educação Física é uma disciplina que tem como finalidade promover o desenvolvimento psicomotor das crianças, ajudando-as a adquirirem uma consciência que as auxiliará em seu cotidiano (SILVA, ET AL, 2011). A Base Nacional Comum Curricular (BNCC) ressalta que a Educação Física oferece uma série de possibilidades para enriquecer a experiência da criança, adolescente, jovens e adultos na educação básica permitindo o acesso a um vasto universo cultural (BRASIL, 2016).

Nesse contexto, observa-se que Educação Física é uma área do conhecimento cujo desenvolvimento deve ser pautado em um currículo previamente estabelecido, cabendo ao professor uma pré-seleção de conteúdos conforme exigência de cada escola e características socioculturais e individuais dos alunos; apresentando-se o planejamento de ensino como uma proposta docente para o pleno desenvolvimento das atividades (CARDOSO, 1999).

Assim, refletir acerca do planejamento constitui recriar os métodos pedagógicos incorporados às teorias educacionais numa perspectiva de significados e consequentemente extinguir a distância entre o planejar e a prática 
efetiva do professor. Sendo assim, é de competência da escola e do docente de Educação Física sistematizar e organizar os conteúdos com a realidade que atua, estabelecendo sobre as melhores condições para o desenvolvimento dos seus alunos.

$\mathrm{O}$ artigo tem como objetivo de analisar o planejamento de ensino de professores de Educação Física do munícipio de Paripiranga-BA. E justifica-se em discutir sobre o ato de planejar as aulas de Educação Física para contribuir no processo de ensino aprendizagem do aluno.

\section{Metodologia}

O estudo caracterizou-se como uma pesquisa de campo com abordagem quantitativa. Segundo Lakatos e Marconi (2010), a pesquisa de campo é utilizada com o objetivo de conseguir informações e/ou conhecimentos acerca de um problema, para o qual se procura uma resposta, ou de uma hipótese, que se queira comprovar. Para Knechtel (2014), a pesquisa quantitativa é uma modalidade de pesquisa composta por variáveis quantificadas em números, as quais são analisadas de modo estatístico, com o objetivo de determinar se as generalizações previstas na teoria se sustentam ou não.

A população foi constituída por professores de Educação Física do município de Paripiranga, Bahia, Brasil. A amostra foi composta por 3 professores licenciados em Educação Física e que atuam na rede municipal de ensino.

Para a coleta de dados foi realizado um questionário com 7 (sete) perguntas abertas sobre a construção do planejamento das aulas de Educação Física. Os entrevistados receberam um Termo de Consentimento Livre e Esclarecido (TCLE) e responderam ao questionário de forma voluntária.

Os dados foram analisados através de estatística descritiva, através do programa Excel 2019.

\section{Resultados e discussão}

Em relação a formação dos professores, verificou-se que todos os docentes 
são formados em Educação Física, exercendo-o de forma legal no ambiente escolar.

Quadro 1: Possui formação em Licenciatura em Educação Física?

\begin{tabular}{|l|l|}
\hline VARIÁVEIS & $\%(\mathrm{n}=3)$ \\
\hline Sim & $100 \%(3)$ \\
\hline Não & - \\
\hline
\end{tabular}

Fonte: Autores, 2019

Destaca-se que a Educação Física é componente obrigatório na educação básica, conforme a Lei $n^{\circ}$ 9.394/96, Art. 26., § 30 que dispõe que “a Educação Física, integrada à proposta pedagógica da escola, é componente curricular obrigatório da educação básica" (BRASIL, 1996).

Quadro 2: Qual a importância da Educação Física Escolar?

\begin{tabular}{|l|c|}
\hline VARIÁVEIS & $\%(n=3)$ \\
\hline Formação de hábitos esportivos para uma vida mais saudável & $66,5 \%(2)$ \\
\hline $\begin{array}{l}\text { Proporcionar aos alunos a vivência de atividades corporais para o } \\
\text { desenvolvimento integral do aluno }\end{array}$ & $33,5 \%(1)$ \\
\hline
\end{tabular}

Fonte: Autores, 2019

No quadro 2, observou-se que 66,5\% (2) dos professores destacaram a importância da Educação Física para formação de hábitos esportivos e 33\% (1) destacou a Educação Física como elemento da cultura corporal do movimento contribuindo no desenvolvimento biopsicossocial.

É importante destacar que de acordo com Zunino (2008), a Educação Física não é desenvolver nos alunos padrões de desenvolvimento motor, mas, a partir de atividades planejadas, favorecer o desenvolvimento de habilidades motoras, capacidades perceptivo-motoras e capacidades físicas e motoras. 
Quadro 3: Como é realizado o planejamento de ensino da Educação Física Escolar?

\begin{tabular}{|l|l|}
\hline VARIÁVEIS & $\%(n=3)$ \\
\hline Com base nos PCNs e nas DCNs & $33 \%(1)$ \\
\hline Com base na BNCC & $33 \%(1)$ \\
\hline Com base em outras pesquisas & $33 \%(1)$ \\
\hline
\end{tabular}

Fonte: Autores, 2019

No quadro 3, observou-se que os professores elaboram o planejamento de acordo com as propostas dos PCNs, DCNs e BNCC e com bases em outras pesquisas. Sendo assim, os documentos legais tornam-se importantes para a construção do planejamento ensino e para que o professor estruture sua aula de acordo com as necessidades, faixa etária e a problematização da turma.

O planejamento é essencial ao professor para manter um acompanhamento de suas atividades didáticas e verificar os resultados provenientes da sua atuação, bem como verificar fragilidades e possibilidades de alterações. Conforme Libâneo (2013) o planejamento de ensino é uma tarefa docente que inclui tanto a previsão das atividades didáticas em termos de sua organização e coordenação em face dos objetivos propostos, quanto a sua revisão e adequação no decorrer do processo de ensino.

Quadro 4: Qual subsídio teórico/abordagem pedagógico é utilizado para o planejamento de ensino da Educação Física Escolar?

\begin{tabular}{|l|l|}
\hline VARIÁVEIS & $\%(\mathrm{n}=3)$ \\
\hline Base Nacional Curricular Comum & $66 \%(2)$ \\
\hline Parâmetros Curriculares Nacionais & $66 \%(2)$ \\
\hline Diretrizes Curriculares Nacionais & $33 \%(1)$ \\
\hline
\end{tabular}

Fonte: Autores, 2019

Em relação ao subsídio teórico/abordagem pedagógica, $66 \%$ (4) dos docentes utilizam a BNCC e os PCNs e 33\% (1) utiliza os DCNs. A Base Nacional Comum Curricular (BNCC) é um documento de caráter normativo que define o conjunto orgânico e progressivo de aprendizagens essenciais que todos os alunos 
devem desenvolver ao longo das etapas e modalidades da Educação Básica, de modo a que tenham assegurados seus direitos de aprendizagem e desenvolvimento, em conformidade com o que preceitua o Plano Nacional de Educação (BRASIL, 2017).

Os Parâmetros Curriculares Nacionais (PCNs) são diretrizes elaboradas pelo Governo Federal com o objetivo principal de orientar os educadores por meio da normatização de alguns fatores fundamentais concernentes a cada disciplina. Esses parâmetros abrangem tanto a rede pública, como a rede privada de ensino, conforme o nível de escolaridade dos alunos, além de auxiliar o professor na tarefa de reflexão e discussão de aspectos do cotidiano da prática pedagógica, a serem transformados continuamente pelo professor (BRASIL, 1998).

Já, as Diretrizes Curriculares Nacional (DCNs) são fundamentadas na Constituição Federal, na LDB e demais leis que buscam organizar e qualificar a Educação Básica do país. Definem-se como um conjunto de princípios, fundamentos e procedimentos capazes de orientar as escolas brasileiras na organização, articulação, desenvolvimento e avaliação de suas propostas pedagógicas (Resolução CNE/CEB nํ2/98).

Quadro 5: Quais os conteúdos da Educação Física você utiliza no planejamento de ensino?

\begin{tabular}{|l|l|}
\hline VARIÁVEIS & $\%(\mathrm{n}=3)$ \\
\hline Práticas esportivas & $33 \%(1)$ \\
\hline Jogos e brincadeiras & $33 \%(1)$ \\
\hline Ginástica & $33 \%(1)$ \\
\hline Esportes & $66 \%(2)$ \\
\hline Atividades rítmicas e expressivas & $33 \%(1)$ \\
\hline Conhecimento sobre o corpo & $33 \%(1)$ \\
\hline
\end{tabular}

Fonte: Autores, 2019

No quadro 5, observou-se o destaque nos esportes, porém é necessário que os professores trabalhem os diversos conteúdos nas aulas de Educação Física para contribuir no desenvolvimento biopsicossocial dos alunos.

Segundo Libâneo (2013), os conteúdos são um conjunto de conhecimentos, 
habilidades, hábitos, modos valorativos e atitudinais de atuação histórico-social, organizados pedagogicamente e didaticamente em matérias de ensino, tendo em vista o processo de construção do conhecimento pelos alunos e suas relações com o contexto vivido.

Quadro 6: Existe material didático adequado para a prática da Educação Física Escolar?

\begin{tabular}{|l|l|}
\hline VARIÁVEIS & $\%(\mathrm{n}=3)$ \\
\hline Sim & - \\
\hline Não & $100 \%(3)$ \\
\hline
\end{tabular}

Fonte: Autores, 2019

No quadro 6, os professores apontaram que não possuem acesso aos materiais adequados para desenvolver suas aulas, necessitando de adaptá-los.

Martins e Felker (2008) afirmam sobre a disponibilidade de recursos materiais para as aulas de Educação Física é tão escassa quanto às instalações desportivas, porém, as aulas acontecem de forma adaptada onde são criadas situações que promovam a inclusão de todos os educandos estimulando o aprendizado e vivências positivas e que ainda os professores procuram fora da escola subsídios de apoio à sua prática docente.

Quadro 7: Existe espaço físico adequado para a prática da Educação Física Escolar?

\begin{tabular}{|l|l|}
\hline VARIÁVEIS & $\%(\mathrm{n}=3)$ \\
\hline Sim & - \\
\hline Não & $100 \%(3)$ \\
\hline
\end{tabular}

Fonte: Autores, 2019

No quadro 7, observou-se que não há espaços físicos adequados para a prática da Educação Física. De acordo com Silveira (2002), a realidade observada nas aulas de Educação Física em caráter nacional evidencia a predominância do esporte, ao mesmo tempo em que os professores são bastante tradicionais na sua 
Revista Multidisciplinar do Nordeste Mineiro, v.2, 2021/02

ISSN 2178-6925

prática pedagógica, gerando certa conveniência, podendo estar relacionada à baixa remuneração, falta de estrutura e material didático, falta de formação continuada e, principalmente, ao não reconhecimento da comunidade e da unidade escolar

\section{Considerações Finais}

A educação estabelece e determina prioridades básicas, organiza ações e meios necessários para a efetivação de metas e objetivos da educação. Sendo assim, o planejamento torna-se essencial para que os objetivos sejam alcançados e proporcionem o desenvolvimento do aluno.

Observou-se na pesquisa pontos positivos no que se refere a formação dos professores em Licenciatura em Educação Física e no planejamento das aulas com base nos PCNs, DCNs e BNCC. Os pontos negativos foram identificados na ausência do espaço físico e de materiais adequados que dificultam no desenvolvimento das aulas.

Conclui-se a necessidade de maiores investimentos para a Educação Física escolar, bem como na oferta de cursos de atualização aos professores, a fim de contribuir em um planejamento significativo para a construção de conhecimentos dos alunos.

\section{Referências}

BRASIL. Base Nacional Comum Curricular. Brasília: MEC, 2017. Disponível em: http://basenacionalcomum.mec.gov.br/images/BNCC El EF 110518 versaofinal s ite.pdf. Acesso em 13/05/2020.

BRASIL. Lei 9.394, de 20 de dezembro de 1996. Estabelece as Diretrizes e Bases da Educação Nacional. Disponível em:

http://www.planalto.gov.br/ccivil 03/leis/L9394.htm. Acesso em: 13/05/2020.

BRASIL. Parâmetros Curriculares Nacionais. Brasília: MEC/SEF, 1998.

Disponível em: http://portal.mec.gov.br/seb/arquivos/pdf/introducao.pdf. Acesso em: 13/05/2020.

BRASIL. Resolução CNE/CP 1/2002, de 18 de fevereiro de 2002. Institui as 
Revista Multidisciplinar do Nordeste Mineiro, v.2,

2021/02

ISSN 2178-6925

Diretrizes Curriculares Nacionais para a formação de professores da educação básica, em nível superior, curso de licenciatura, de graduação plena. Disponível em: http://portal.mec.gov.br/cne/arquivos/pdf/rcp01 02.pdf. Acesso em: 13/05/2020.

COLETIVO DE AUTORES. Metodologia do Ensino da Educação Física. $2^{\mathrm{a}}$ ed. São Paulo: Cortez, 2012.

CUNHA, M. I. O bom professor e sua prática. 24. ed. Campinas: Papirus, 2012.

GANDIN, D. Planejamento como prática educativa. 9.ed. São Paulo: Loyola, 1997.

KNECHTEL, Maria do Rosário. Metodologia da pesquisa em educação: uma abordagem teórico-prática dialogada. Curitiba: Intersaberes, 2014.

LAKATOS, Eva Maria; MARCONI, Marina de Andrade. Fundamentos da metodologia científica. 7. ed. São Paulo: Atlas, 2010.

LIBÂNEO, J.C. Didática. São Paulo: Cortez, 2013.

MARTINS, L.; FELKER. Estudo diagnóstico sobre a Educação Física nas escolas públicas nas séries iniciais de ensino fundamental no município de Arroio do Sal.

Rev. Cinergis, v. 9, n. 2, p. 1-14, 2008.

MELLO, M. T, TUFIK S. Atividade física, exercício físico e aspectos psicobiológicos. Ed. Guanabara, 2004.

SILVEIRA, J. A. Educação Física Escolar nas escolas públicas e os seus conteúdos: uma análise sobre a postura dos educadores acerca de seu campo de trabalho. Niterói, 2002.

TRIVIÑOS, A. Introdução à pesquisa em ciências sociais: a pesquisa qualitativa em educação. São Paulo, Atlas, 1987.

ZUNINO, A. Educação física: ensino fundamental, 6ํㅡ - 9․ Curitiba: Positivo, 2008. 